\title{
Elaboração de farinhas de Camarão da Amazônia (Macrobrachium amazonicum) e suas aplicações em sopas instantâneas
}

\author{
Preparation of Amazon Shrimp (Macrobrachium amazonicum) flours and their applications in \\ instant soup \\ Elaboración de harinas de Camarón Amazónico (Macrobrachium amazonicum) y sus aplicaciones
} en sopa instantánea

\section{Resumo}

Os resíduos de camarão possuem alto valor nutricional, podendo ser transformados em farinhas para o consumo humano, com viabilidade de inclusão e enriquecimento de produtos alimentícios. O objetivo deste trabalho foi desenvolver sopa instântanea a base de farinhas de camarões, gerando uma alternativa para aproveitamento de resíduo do processamento. Foram elaboradas três diferentes farinhas de camarão da Amazônia (Macrobrachium amazonicum), sendo o tratamento 1= farinha do camarão da Amazônia inteiro (FCI), tratamento 2 = farinha do camarão da Amazônia 
inteiro limpo (FCL) e tratamento 3 = farinha do resíduo do camarão da Amazônia inteiro (FRC), que foram incluídas em sopas instantâneas, com posterior caracterização da composição centesimal e sensorial. As farinhas e as sopas estavam dentro dos padrões microbiológicos. A farinha de camarão limpo apresentou maior teor de proteína bruta $(87,32 \%)$ e a farinha de resíduos de camarão os maiores teores de cinzas e carboidratos, $22,59 \%$ e $17,06 \%$, respectivamente. Quanto à umidade e aos lipídeos totais, não houve diferenças significativas entre as farinhas elaboradas. A sopa instantânea com a FCL apresentou o maior teor de proteína $(23,42 \%)$ e o menor teor de cinzas $(5,75 \%)$. Mas, em relação a análise sensorial foi a sopa com inclusão de FRC que apresentou as melhores notas para os atributos aroma, impressão global e intenção de compra, enquanto para os demais não houve diferença significativa. Assim, os resíduos gerados no processamento do camarão podem ser utilizados para elaborar farinhas de elevado valor nutricional, para a inclusão em diversos produtos alimentícios comumente consumidos pela população, como sopas instantâneas.

Palavras-chave: Análise sensorial; Composição química; Microbiologia; Resíduos do processamento.

\begin{abstract}
Shrimp residues have a high nutritional value and can be transformed into flour for human consumption, with feasibility of inclusion and enrichment of food products. The objective of this work was to develop instant soup based on shrimp flour, generating an alternative for the use of processing residue. Three different Amazon shrimp flours (Macrobrachium amazonicum) were prepared, with treatment $1=$ whole Amazon shrimp flour (FCI), treatment $2=$ whole Amazon shrimp flour cleaned (FCL) and treatment 3 = flour from the residue of the Whole Amazon Shrimp (FRC), which were included in instant soups, with subsequent characterization of proximate and sensory composition. The flours and soups were within microbiological standards. The clean shrimp meal had the highest crude protein content (87.32\%) and the shrimp residue meal the highest levels of ash and carbohydrates, $22.59 \%$ and $17.06 \%$, respectively. As for moisture and total lipids, there were no significant differences between the processed flours. The instant soup with FCL had the highest protein content $(23.42 \%)$ and the lowest ash content $(5.75 \%)$. But, in relation to sensory analysis, it was the soup with FRC inclusion that presented the best grades for the attributes aroma, global impression and purchase intention, while for the others there was no significant difference. Thus, the waste generated in the processing of shrimp can be used to prepare flours with high nutritional value, for inclusion in various food products commonly consumed by the population, such as instant soups.
\end{abstract}

Keywords: Sensory analysis; Chemical composition; Microbiology; Processing residues.

\title{
Resumen
}

Los residuos de camarón tienen un alto valor nutricional y pueden transformarse en harina para consumo humano, con factibilidad de inclusión y enriquecimiento de productos alimenticios. El objetivo de este trabajo fue desarrollar sopa instantánea a base de harina de camarón, generando una alternativa para el aprovechamiento de residuos de procesamiento. Se prepararon tres harinas diferentes de camarón amazónico (Macrobrachium amazonicum), con tratamiento 1 = harina integral de camarón amazónico (FCI), tratamiento 2 = harina integral de camarón amazónico limpia (FCL) y tratamiento 3 = harina del residuo del camarón integral amazónico (FRC) ), que se incluyeron en sopas instantáneas, con posterior caracterización de composición proximal y sensorial. Las harinas y sopas estaban dentro de los estándares microbiológicos. La harina de camarón limpio tuvo el mayor contenido de proteína cruda (87,32\%) y la harina de residuos de camarón los niveles más altos de cenizas y carbohidratos, 22,59\% y 17,06\%, respectivamente. En cuanto a humedad y lípidos totales, no hubo diferencias significativas entre las harinas preparadas. La sopa instantánea con FCL tuvo el mayor contenido de proteínas $(23,42 \%)$ y el menor contenido de cenizas $(5,75 \%)$. Pero, en relación al análisis sensorial, fue la sopa con inclusión de FRC la que presentó las mejores puntuaciones para los atributos aroma, impresión global e intención de compra, mientras que para las demás no hubo diferencia significativa. Así, los residuos generados en el procesamiento del camarón pueden ser utilizados para preparar harinas con alto valor nutricional, para su inclusión en diversos productos alimenticios comúnmente consumidos por la población, como las sopas instantáneas. Palabras clave: Análisis sensorial; Composición química; Microbiología; Residuos de procesamiento.

\section{Introdução}

O camarão da Amazônia (Macrobrachium amazonicum) vêm se destacando na carcinicultura brasileira, por conter características de fácil adaptação e boas condições de cultivo (Mole \& Bunge, 2003; Roversi, 2018). A espécie é nativa do Brasil e encontrada em ambientes de água doce, largamente distribuída na América do Sul (Furuya et al., 2006). Também conhecido como camarão sossego (Coelho et al., 1982; Maciel \& Valenti, 2009), esta espécie possui grande valor biológico, econômico e social, principalmente nos estados da região norte, devido ao seu alto valor comercial (Collart \& Magalhães, 1994).

O camarão da Amazônia é comumente encontrado em feiras e mercados, e sua principal forma de comercialização é limpo ou polpa, onde só se tem a carne. O resíduo gerado durante o processamento industrial do camarão é cerca de 40-50\% do 
seu peso total, sendo este subproduto consistindo na cabeça, casca e cauda (Ogawa et al., 2007; Sánchez-Camargo et al., 2011). Estes resíduos, que habitualmente são descartados, possuem alto teor de proteína e cinzas (Sánchez-Camargo et al., 2011), podendo ser aproveitado para elaboração de farinhas para a alimentação humana e de animais (Guimarães et al., 2008).

A farinha de pescado é um novo produto que vem sendo estudado para inclusão em processados para alimentação humana, podendo-se agregar valor comercial a espécies pouco apreciadas pelo mercado (Goes et al., 2016), além de representar uma alternativa para o aumento do consumo de pescado. A mesma tecnologia empregada para a farinha de peixe pode ser utilizada na elaboração de farinha de camarão. Esta farinha pode ser usada para enriquecer nutricionalmente outros produtos alimentícios, como sopas instantâneas.

A sopa é um alimento que se faz pela combinação de ingredientes como carne, vegetais em caldo ou água quente / fervente, até que o sabor seja extraído, formando um caldo. As misturas de sopas secas são, atualmente, um item alimentar bem estabelecido nos mercados mundiais de alimentos, principalmente pela praticidade e viabilidade de armazenagem por longos períodos (Rahman et al., 2012). A viabilidade do uso de farinhas de peixes como ingredientes para sopas instantâneas foi demonstrada por Monteiro et al. (2014), Islam et al. (2018) e Souza et al. (2021).

Percebe-se que, atualmente, o mercado de alimentos vem procurando meios de desenvolver produtos mais práticos e que satisfaçam os anseios do mercado consumidor, com altos valores nutricionais. Desta forma, o objetivo deste trabalho foi elaborar e caracterizar farinhas de camarão da Amazônia, gerando uma alternativa para aproveitamento de resíduo do processamento animal, seguido da avaliação de composição nutricional, microbiológica e a análise sensorial da sopa instantânea com a inclusão dessas farinhas.

\section{Metodologia}

\section{Origem da matéria prima e execução do experimento}

O experimento foi realizado no laboratório de Tecnologia do Pescado na Fazenda Experimental de Iguatemi (FEI), pertencente à Universidade Estadual de Maringá (UEM), onde foi elaborada e caracterizada as farinhas de camarão da Amazônia (Macrobrachium amazonicum) e as sopas instantâneas. A matéria-prima para a produção da farinha foi adquirida com pescadores da região de Santana no Amapá. O camarão foi transportado e mantido a uma temperatura de $-5^{\circ} \mathrm{C}$ até o momento da elaboração das farinhas.

\section{Elaboração das farinhas de camarão}

Foram elaboradas três diferentes farinhas, sendo o tratamento 1= farinha do camarão da Amazônia inteiro (FCI), tratamento 2 = farinha do camarão da Amazônia limpo (sem a carapaça e cefalotórax) (FCL) e tratamento 3 = farinha do resíduo do camarão da Amazônia (carapaça e cefalotórax) (FRC).

Para a produção da farinha foram utilizados $2 \mathrm{Kg}$ de matéria-prima para cada tratamento, sendo que para a FCI utilizouse o camarão inteiro, para a FCL apenas a carne do camarão e para a FRC os resíduos remanescentes da limpeza do camarão (carapaça e cefalotórax). Para elaboração de todas as farinhas, as matérias-primas foram sanitizadas e cozidas em panela de pressão por 60 minutos, com 0,1\% de peroxitane, $0,5 \%$ de BHT e 100\% de água, depois moídas em moedor de carne, prensadas em prensa hidráulica a 10 toneladas, desidratadas por 24 horas a $55^{\circ} \mathrm{C}$ e moídas novamente em moedor. As farinhas prontas foram embaladas a vácuo e armazenadas em freezer $\left(-18^{\circ} \mathrm{C}\right)$ até o momento das análises e preparação das sopas instantânea.

\section{Elaboração das sopas instantâneas com a inclusão das diferentes farinhas de camarão}

Na elaboração das sopas, foram utilizados $10 \%$ de inclusão das farinhas de camarão perfazendo três tratamentos, sendo tratamento 1= sopa de farinha de camarão da Amazônia limpo, tratamento 2= sopa de farinha de camarão da Amazônia inteiro 
e tratamento 3= sopa de farinha de resíduo de camarão da Amazônia.

Para a elaboração da sopa adicionaram-se os seguintes ingredientes desidratados: legumes, alho, cebola, cebolinha, coentro, cheiro verde, salsa, sal, pimenta do reino, colorau, glutamato monossódico e cominho. Após a homogeneização, as sopas foram embaladas a vácuo e acondicionadas a temperatura de $5-7^{\circ} \mathrm{C}$ até o momento de realização das análises.

\section{Análises microbiológicas das farinhas e sopas instantâneas}

As análises microbiológicas foram realizadas no laboratório de Microbiologia e Microscopia de Alimentos, do Departamento de Análises Clínicas na Universidade Estadual de Maringá (UEM). Foi reservado em geladeira aproximadamente $100 \mathrm{ml}$ de todos os tratamentos da sopa e $100 \mathrm{~g}$ de farinha de camarão para realização das análises de determinação do número mais provável (NMP) de coliformes a $35^{\circ} \mathrm{C}$ e $40^{\circ} \mathrm{C}$, contagem de Estafilococos coagulase positiva em unidade formadora de colônia (UFC)/grama e de Salmonella spp em 25g de amostra, de acordo com APHA (2001).

O protocolo microbiológico seguiu os padrões recomendados pela Resolução RDC n ${ }^{\circ} 12$, de 2 de janeiro de 2001, da Agência Nacional de Vigilância Sanitária (Brasil, 2001). Essas análises microbiológicas foram realizadas apenas para caracterização dos produtos se estavam aptos para consumo humano, portanto não houve a realização de análise estatística.

\section{Análises de composição centesimal e pH}

Para a avaliação da composição centesimal das farinhas e da sopa instantânea foram realizadas análises de umidade, proteína bruta, lipídeos e cinzas. As determinações foram feitas em triplicata a partir de amostras de $100 \mathrm{~g}$.

O teor de proteína bruta foi obtido pelo processo semi-micro Kjeldahl, em três etapas distintas (digestão, destilação e titulação), segundo Silva \& Queiroz (2002). A umidade e as cinzas foram realizados segundo metodologia da AOAC (2005). O teor de lipídios totais foi determinado pela metodologia Bligh \& Dyer (1959). A determinação da fração de carboidratos das amostras foi realizada por diferença, como mostra a equação: $\mathrm{CHO}=100$ - (UM+MM+PB+EE). Onde: $\mathrm{CHO}=$ Carboidratos; $\mathrm{UM}=$ Umidade $; \mathrm{MM}=$ Matéria mineral $; \mathrm{PB}=$ Proteína bruta e EE = Extrato etéreo.

Para obtenção do $\mathrm{pH}$ das sopas instantâneas, foram homogeneizados $5 \mathrm{~g}$ de amostras na proporção 1:2 com água destilada e submetidas a leitura em pHmetro (DM 22, Digimed).

\section{Análise sensorial das sopas instantâneas}

Os métodos da análise sensorial foram aprovados pelo Comitê Permanente de Ética em Pesquisa com Seres Humanos da Universidade Estadual de Maringá, Maringá PR Brazil (Protocolo CAAE: 14219213.1.0000.0104).

A análise sensorial da sopa instantânea, foi realizada com 80 provadores não treinados, onde foram fornecidas em torno de $20 \mathrm{ml}$ de amostra de cada sopa instantânea em copo descartável de cada tratamento, identificadas com números aleatórios. Juntamente com as amostras identificadas referentes a cada tratamento foi fornecido uma ficha para realização da análise sensorial e um copo com água para remover o sabor residual.

Os provadores avaliaram as sopas instantâneas quanto aos aspectos sensoriais de cor, aroma, sabor, textura e impressão global, baseada em uma escala hedônica estruturada de 9 pontos, ancorada entre mínimo e máximo: 1 (desgostei extremamente) e 9 (gostei extremamente) (Dutcosky, 2013). As amostras também foram submetidas ao teste de intenção de compra, com escala hedônica de 5 pontos com os extremos 1 (certamente não compraria) e 5 (certamente compraria) (Damasio \& Silva, 1996).

\section{Análise estatística}

Foi realizado em delineamento inteiramente casualizado para as análises dos dados. Os dados foram submetidos à análise de variância (ANOVA) e as médias comparadas pelo teste de Tukey, ao nível de 5\% de probabilidade, utilizando o 
programa computacional Statistical Analysis System (SAS, SAS Inst. Inc. Cary, NC, USA).

\section{Resultados e Discussão}

\section{Análises microbiológicas das farinhas e sopas instantâneas}

As análises microbiológicas das farinhas de camarão da Amazônia e das sopas instantâneas estão apresentadas na Tabela 1.

Tabela 1. Análise microbiológica das farinhas do camarão da Amazônia (Macrobrachium amazonicum) e das sopas instantâneas.

\begin{tabular}{llll}
\hline Farinhas & $\begin{array}{l}\text { Coliformes a } 35{ }^{\circ} \mathrm{C} \text { e } 45{ }^{\circ} \mathrm{C} \\
\left(\mathrm{NMP}^{2} / \mathrm{g}\right)\end{array}$ & $\begin{array}{l}\text { Estafilococos coagulase positiva } \\
\left(\mathrm{UFC}^{3} / \mathrm{g}\right)\end{array}$ & $\begin{array}{c}\text { Salmonella spp } \\
\text { FCI }\end{array}$ \\
\hline 3 & $1 \times 10^{2}$ & Ausente \\
FCL & $<3$ & $1 \times 10^{2}$ & Ausente \\
FRC & $<3$ & $1 \times 10^{2}$ & Ausente \\
\hline Sopas Instantânea & & & Ausente \\
\hline Sopa com FCI & $<3$ & $1 \times 10^{2}$ & Ausente \\
Sopa com FCL & $<3$ & $1 \times 10^{2}$ & Ausente \\
Sopa com FRC & $<3$ & $1 \times 10^{2}$ & \\
\hline
\end{tabular}

${ }^{1}$ FCI = Farinha de camarão da Amazônia inteiro; FCL=Farinha de camarão da Amazônia limpo; FRC= Farinha de resíduo de camarão da Amazônia. ${ }^{2} \mathrm{NMP}=$ Número mais provável. ${ }^{3} \mathrm{UFC}=$ Unidade formadora de colônia. Fonte: Elaborada pelos autores (2021).

Com as análises microbiológica observou-se que tanto as farinhas de camarão da Amazônia, quanto as sopas instantâneas estavam dentro dos padrões estabelecidos pela legislação brasileira, conforme RDC nº 12, da Agência Nacional de Vigilância Sanitária do Ministério da Saúde (Brasil, 2001). Para produtos à base de pescados, esta resolução estabelece número máximo de $10^{3} \mathrm{NMP} / \mathrm{g}$ para coliformes a $45^{\circ} \mathrm{C}, 10^{3} \mathrm{UFC} / \mathrm{g}$ para Estafilococos coagulase positiva e ausência de Salmonella spp em $25 \mathrm{~g}$ (Brasil, 2001). Tais resultados demonstram que os produtos foram produzidos dentro das condições exigidas de higiene, portanto estavam aptos para o consumo humano.

\section{Análises de composição centesimal, valor calórico e pH}

Para a composição centesimal, os resultados estão apresentados na Tabela 2, demonstrando os valores de umidade, proteína bruta, lipídios totais, cinzas, carboidratos e valor calórico para farinha camarão da Amazônia (Macrobrachium amazonicum) e das sopas instantâneas.

Tabela 2. Composição centesimal das farinhas de camarão da Amazônia (Macrobrachium amazonicum) e das sopas instantâneas.

\begin{tabular}{llllll}
\hline Farinhas & Umidade (\%) & Proteína (\%) & Lipídeos totais (\%) & Cinzas (\%) & Carboidratos (\%) \\
\hline FCI $^{1}$ & $0,86 \pm 0,14$ & $79,76 \pm 4,91^{\mathrm{b}}$ & $3,24 \pm 0,42$ & $15,53 \pm 1,89^{\mathrm{b}}$ & $1,67 \pm 4,58^{\mathrm{b}}$ \\
FCL & $0,59 \pm 0,13$ & $87,32 \pm 12,47^{\mathrm{a}}$ & $3,07 \pm 0,25$ & $14,15 \pm 3,27^{\mathrm{b}}$ & $0,10 \pm 6,25^{\mathrm{a}}$ \\
FRC & $0,72 \pm 0,01$ & $57,46 \pm 17,39^{\mathrm{c}}$ & $2,15 \pm 0,67$ & $22,59 \pm 4,87^{\mathrm{a}}$ & $17,06 \pm 10,81^{\mathrm{c}}$ \\
\hline Valor de p. & 0,3452 & 0,0000 & 0,1147 & 0,0005 & 0,0000 \\
\hline C.V. (\%) & 21,32 & 0,66 & 13,31 & 17,42 & 1,21 \\
\hline Sopa Instantânea & & & & & \\
\hline Sopa de FCI & $7,95 \pm 0,52^{\mathrm{b}}$ & $21,81 \pm 0,19^{\mathrm{b}}$ & $2,05 \pm 0,43$ & $8,02 \pm 0,65^{\mathrm{a}}$ & $60,15 \pm 0,48$ \\
Sopa de FCL & $8,14 \pm 0,33^{\mathrm{b}}$ & $23,42 \pm 1,42^{\mathrm{a}}$ & $2,63 \pm 0,15$ & $5,75 \pm 1,62^{\mathrm{b}}$ & $60,05 \pm 0,38$ \\
Sopa de FRC & $9,29 \pm 0,82^{\mathrm{a}}$ & $20,79 \pm 1,21^{\mathrm{b}}$ & $2,76 \pm 0,02$ & $8,32 \pm 0,95^{\mathrm{a}}$ & $60,15 \pm 0,48$ \\
\hline Valor de p. & 0,0018 & 0,0174 & 0,2354 & 0,0007 & 0,4260 \\
\hline C.V. $(\%)^{2}$ & 1,21 & 5,45 & 4,73 & 1,99 & 1,69 \\
\hline
\end{tabular}

${ }^{1}$ FCI = Farinha de camarão da Amazônia inteiro; FCL=Farinha de camarão da Amazônia limpo; FRC= Farinha de resíduo de camarão da Amazônia; ${ }^{2}$ C.V.= Coeficiente de variação. Dados expressos em média \pm desvio padrão. Médias seguidas de letras diferentes na mesma coluna, diferem entre si pelo Teste de Tukey. Fonte: Elaborada pelos autores (2021). 
Os resultados da farinha de camarão demostram que não houve diferença significativa para os parâmetros de umidade e lipídeos totais, as quais apresentaram um valor médio de $0,72 \%$ e $2,82 \%$, respectivamente. Geralmente produtos oriundos de pescado apresentam valores altos de umidade, que não são desejáveis, pois ela propicia uma rápida deterioração e contaminação (Damasceno, 2007). Todavia, neste caso os produtos são desidratados, esperando-se com isso baixíssimo teor de umidade associado ao tipo de matéria prima utilizada. Souza et al. (2021) elaboraram farinhas de peixes (tilápia, atum e salmão) e estes apresentaram maiores teores de umidade variando de 6,32\% a 9,50\% em função da espécie de peixe utilizada e processo de elaboração desse produto.

Os teores de lipídeos das diferentes farinhas e sopas não foram diferentes entre si ( $\mathrm{P}>, 05)$, com média de 2,82\% para as farinhas e 2,48\% para as sopas. Os lipídeos têm papel fundamental para o organismo, como atuar no armazenamento de energia, auxiliar na absorção de vitaminas lipossolúveis e fornecer ácidos graxos essenciais (Leningher et al., 1995). Em especial, os lipídeos encontrados no camarão da Amazônia (M. amazonicum) são boas fontes de ácidos graxos n-3, sendo os ácidos docosahexaenóico e eicosapentaenóico os ácidos graxos poli-insaturados dominantes (Portella et al., 2013). Sabe-se que esses ácidos graxos são essenciais na nutrição humana e provaram estar envolvidos em muitas funções metabólicas, além de ter efeitos anti-inflamatórios, diminuírem a agregação plaquetária e serem peças essenciais nas membranas celulares, sistema cardiovascular, cérebro e tecido nervoso (Tilami \& Sampels, 2018). Existem recomendações diárias de lipídeos, que devem ser fornecidas através dos alimentos. O percentual de lipídeos do presente trabalho está superior aos encontrados em alguns produtos, como por exemplo em bolinhos de camarão elaborados com e sem alga marinha. Estes apresentaram os valores de 1,83 e 1,07\% de lipídeos, respectivamente segundo Vasconcelos (2015). Souza et al. (2021) também reataram teores de 6,07\% a 12,85\% para as farinhas com diferentes espécies de peixes e quando colocadas em sopa instantâneas com a inclusão dessas farinhas foi para $5,33 \%$ a $6,5 \%$.

Em relação ao teor de proteína bruta, o tratamento FCL e FCI apresentaram maiores teores de proteína de 87,32\% e $79,76 \%$, respectivamente, o tratamento FRC apresentou o menor teor de 57,46\%, isso se deve a matéria-prima utilizada, pois neste foi apenas a carapaça e cefalotórax enquanto o FCL, com maior teor de proteína, utilizou-se somente a carne do camarão.

$\mathrm{O}$ valor de alto teor proteico nos tratamentos FCL e FCI deve-se principalmente quantidade de carne presente no produto. Sendo que no tratamento FRC ocorreu o inverso, sem a presença de carne, que seria o principal responsável pelo teor proteína. No entanto, não pode deixar de considerar que no cefalotórax existem órgãos do trato digestório, reprodutivo e principalmente lembrando-se do hepatopâncreas que tem grande contribuição no teor de proteína nesse tipo de farinha, onde chegou a $57,46 \%$.

A farinha utilizando o resíduo do camarão apresentou as maiores quantidades de cinzas e carboidratos em sua composição, 22,59\% e 17,06\%, respectivamente. Os resultados de teor de cinzas encontrados por Assunção e Pena (2007), foram semelhantes aos valores obtidos no tratamento FRC, onde o autor trabalhou com resíduos seco de cabeça de camarão-rosa, e o teor de cinzas foi de $22,01 \%$. O fato se deve pelo resíduo usado, que é composto em grande parte pelo exoesqueleto do animal, parte essa rica em minerais e quitina. Segundo Boscolo et al. (2004) a farinha de camarão canela inteiro contém 14,26\% de cinzas, valor menor que o encontrado para a farinha de resíduo de camarão no presente trabalho que foi de 22,59\%. Os minerais são elementos essenciais para a manutenção dos processos metabólicos, que fazem parte da ação de algumas enzimas que são responsáveis pela regulação das atividades fisiológicas (Viebig \& Nacif, 2007). Portanto, o consumo de farinha de camarão contribui com esse teor necessário de minerais ao organismo.

As sopas apresentaram diferença significativa para os teores de umidade, proteína e cinzas. A sopa com a inclusão da FRC apresentou 9,29\% de umidade, sendo superior as demais sopas. Quanto ao teor de proteína foi maior para a sopa com inclusão de FCL, por ser apenas a farinha com a carne do camarão, sendo resultado inverso para os teores de cinzas, ou seja, a sopa com FCL apresentou menor teor de cinzas (5,75\%), enquanto a sopa com FRC o maior teor $(8,32 \%)$ decorrente da 
quantidade de carapaça e cefalotórax presente na farinha elaborada com esse tipo de matéria prima. Para os teores de lipídeos e carboidratos não houve diferença significativa.

Souza et al. (2021) analisando a sopa instantânea com inclusão da farinha de peixes de diferentes espécies relataram que as sopas apresentaram $22,40 \%$ a $23,24 \%$ de umidade, $11,11 \%$ a $11,57 \%$ de proteína, 5,33\% a 6,90\% de lipídeos, 9,84\% a $10,66 \%$ de cinzas e $48,97 \%$ a $49,64 \%$ de carboidratos. Observando esses resultados relatados pelos autores supracitados nota-se que a sopa com farinha de camarão apresentou maiores teores de proteína e carboidratos, enquanto os teores de umidade, lipídeos e cinzas foram menores. Parte destes resultados podem estar associados ao menor teor de umidade da sopa, que neste experimento foi e 7,95\% a 9,29\% proporcionando uma maior concentração nos teores de proteína do produto. Quanto aos teores de lipídeos e cinzas não houve maior concentração desses nutrientes, por estarem realmente em menor proporção na própria farinha. Visto que nas farinhas elaborada por Souza et al. (2021) esses teores foram muito superiores (lipídeos de 6,07\% a 12,85\% e cinzas de $29,25 \%$ a 33,31\%) aos obtidos para farinha de camarão (Tabela 2).

Stevanato et al. (2007) elaboraram farinha de cabeça de tilápia para incluir em sopas. Os autores relataram que a farinha apresentou 6,0\% de umidade, $38,4 \%$ de proteína, $19,4 \%$ de cinzas e 35,5\% de lipídeos, enquanto a sopa pronta para consumo com $81,67 \%$ de umidade, 2,12\% de cinzas, 2,92\% de proteína e 4,26\% de lipídeos. Mas, comparando os resultados das farinhas de camarão com os resultados da farinha de cabeça de tilápia relatado por Stevanato et al. (2007), observa-se que na de camarão por menor quantidade de proteína (FRC), ainda foi superior ao de cabeça de tilápia, assim como menores teores de cinzas e lipídeos para as farinhas de camarão comparado a mencionada pelos autores supracitados.

Através dos resultados obtidos neste trabalho e comparando-os com os obtidos na literatura, nota-se que a espécie utilizada e forma que se encontra a matéria prima (inteira, parcial ou apenas os resíduos) na elaboração da farinha, assim como, as condições finais do produto (nutrientes da farinha) para a sua inclusão na sopa, nível de inclusão (mesmo a quantidade de inclusão) na sopa instantânea interfere muito nos valores nutricionais do produto final.

Os valores médios encontrados para o pH das farinhas e sopas foi de 6,65 onde se obteve pouca variação, sendo considerado um pH neutro.

\section{Análise sensorial das sopas instantâneas}

Os resultados obtidos na análise sensorial das sopas instantâneas de camarão da Amazônia estão demostrados na Tabela 3. Foram avaliados os atributos: cor, sabor, aroma e textura, sendo avaliado também impressão global e intenção de compra.

Tabela 3. Análise sensorial de sopa de camarão da Amazônia (Macrobrachium amazonicum).

\begin{tabular}{|c|c|c|c|c|c|c|}
\hline Produtos & Cor & Sabor & Aroma & Textura & $\begin{array}{l}\text { Impressão } \\
\text { global }\end{array}$ & $\begin{array}{ll}\begin{array}{l}\text { Intenção } \\
\text { compra }\end{array} & \text { de }\end{array}$ \\
\hline Sopa FCL ${ }^{1}$ & $7,53 \pm 0,19$ & $7,40 \pm 0,38$ & $6,80 \pm 0,42^{b}$ & $7,80 \pm 0,57$ & $7,00 \pm 0,38^{b}$ & $3,50 \pm 0,28^{b}$ \\
\hline Sopa FCI & $7,33 \pm 0,01$ & $6,73 \pm 0,29$ & $7,03 \pm 0,19^{\mathrm{ab}}$ & $6,93 \pm 0,30$ & $7,13 \pm 0,25^{\mathrm{b}}$ & $3,50 \pm 0,28^{b}$ \\
\hline Sopa FRC & $7,16 \pm 0,18$ & $6,93 \pm 0,09$ & $7,83 \pm 0,61^{\mathrm{a}}$ & $6,97 \pm 0,26$ & $8,00 \pm 0,62^{\mathrm{a}}$ & $4,33 \pm 0,55^{\mathrm{a}}$ \\
\hline Valor de $p$ & 0,5270 & 0,2807 & 0,0143 & 0,0670 & 0,0055 & 0,0091 \\
\hline C.V.2 ${ }^{2}(\%)$ & 17,04 & 23,50 & 19,46 & 22,26 & 17,16 & 31,30 \\
\hline
\end{tabular}

${ }^{1} \mathrm{FCI}=$ Farinha de camarão da Amazônia inteiro; FCL=Farinha de camarão da Amazônia limpo; FRC= Farinha de resíduo de camarão da Amazônia; ${ }^{2}$ C.V.= Coeficiente de variação; Dados expressos em média \pm desvio padrão. Médias seguidas de letras diferentes na mesma coluna, diferem entre si pelo Teste de Tukey. Fonte: Elaborada pelos autores (2021).

A análise de variância mostrou diferença significativa $(\mathrm{p}<0,05)$ entre os tratamentos para aroma, impressão global e intenção de compra, sendo que as variáveis com melhores resultados foram para a sopa com inclusão da farinha de resíduos de camarão. Tal fato mostra que o resíduo teve maior aceitabilidade podendo ser explorado pela indústria de beneficiamento para a produção de um novo produto agregando valor a um resíduo até então não aproveitado com esse objetivo. Desta forma, a 
utilização de subproduto de resíduo de camarão é uma alternativa viável para a introdução de um novo produto que se apresenta prático, e com bom teor proteico.

Souza et al. (2021) analisando sopa instantânea com inclusão de farinha de peixe, relataram que as notas variaram de 5,20 a 7,46, pela escala hedônica de 9 pontos e para a intenção de compra notas de 3,02 a 3,84 quando a escala hedônica aplicada foi de 5 pontos. No entanto, apenas para sabor, impressão global e intenção de compra houve diferença significativa entre os tratamentos.

As sopas que foram elaboradas com farinha de tilápia e farinha de tilápia defumada receberam as melhores notas pelos avaliadores independentes dos atributos avaliados. Segundo os autores, o sabor de peixe difere do que a população normalmente consome no dia a dia, em especial para sopa. Esse tipo de ingrediente para sopa é algo inovador, necessitando de mais trabalhos com inclusão de peixe em sopas ou em outros produtos alimentícios. Portanto, o mesmo pode ser levado em consideração para camarão e principalmente quanto ao aproveitamento de resíduos de processamento do camarão. Mas, quando levado em consideração o valor nutricional do produto obtido, a inclusão de pescado em sopas é uma boa alternativa, principalmente para crianças, idosos e convalescentes, em função do alto valor biológico da proteína, minerais e até o ômega 3 e 6 presentes no crustáceo.

As notas para sabor $(7,83)$ e impressão global $(8,0)$ obtidas na sopa instantânea com a inclusão da FRC, considerando a classificação de Dutcosky (2013), corresponde a gostei muito e as notas de intenção de compra $(4,33)$ para esta mesma sopa, segundo Damasio e Silva (1996) corresponde a possivelmente compraria. Portanto, as sopas instantâneas apresentaram boas notas, mas em função do sabor e impressão global da sopa instantânea a elaborada com farinha de resíduos de camarão apresentou as melhores notas, inclusive para a intenção de compra do produto.

Considerando que no processamento do camarão, são geradas elevadas quantidade de resíduos sólidos, sendo a cabeça (cefalotórax) e a casca do animal (carapaça), que segundo Gildberg e Stenberg (2001) correspondem aproximadamente a 40\% do peso total. Estes resíduos, de acordo com estes autores é composto de 70 a $75 \%$ de água. Esse tipo de resíduos normalmente é enterrado ou jogado no mar ou rios, levando a problemas ambientais, em especial em países grandes produtores de camarão, onde muitas vezes não há um rigor na fiscalização ambiental. Mas, sabe-se que estes resíduos são constituídos de quitina, proteínas, carbonato de cálcio e pigmentos, despertando interesse em seu reaproveitamento, buscando alternativas para desenvolvimento de produtos de valor agregado (Zakaria et al., 1998).

\section{Conclusão}

As farinhas de camarão da Amazônia (Macrobrachium amazonicum) e as sopas instantâneas apresentaram um alto valor nutritivo, principalmente em relação ao valor proteico, pois independentemente do tipo de farinha de camarão utilizada, a sopa apresentou acima de $20 \%$ de proteína. A farinha de resíduos de camarão apresentou um excelente valor nutritivo, devido ao seu elevado teor proteico, cinzas (minerais) e lipídeos. As sopas estavam dentro dos padrões microbiológicos estabelecidos pela legislação. A sopa instantânea a elaborada com farinha de resíduos de camarão apresentou melhor aceitação sensorial. Assim, a inclusão da farinha de resíduos de camarão em produtos alimentícios, como a sopa instantânea é uma alternativa para a utilização e agregação de valor aos resíduos da indústria.

\section{Referências}

American Public Health Association -APHA. (2001). Compendium of methods for the microbiological examination offoods. APHA

Assunção, A. B., \& Pena, R. D. S. (2007). Comportamento higroscópico do resíduo seco de camarão-rosa. Food Science and Technology, 27(4), 786-793. https://doi.org/10.1590/S0101-20612007000400018 
Bligh, E. G \& Dyer, W. J. (1959). A rapid method of total lipid extraction and purification. Canadian Journal of Biochemistry and Physiology, 37(8), 911-17. https://doi.org/10.1139/o59-099

Boscolo, W. R., Hayashi, C., Meurer, F., Feiden, A., \& Bombardelli, R. A. (2004). Digestibilidade aparente da energia e proteína das farinhas de resíduo da filetagem da tilápia do Nilo (Oreochromis niloticus) e da corvina (Plagioscion squamosissimus) e farinha integral do camarão canela (Macrobrachium amazonicum) para a tilápia do Nilo. Revista Brasileira de Zootecnia, 33(1), 8-13. https://doi.org/10.1590/S1516-35982004000100002

Brasil. (2001). Ministério da Saúde. Agência Nacional de Vigilância Sanitária. Resolução RDC n. 12, de 02 de janeiro de 2001.Regulamento Técnico sobre os padrões microbiológicos para alimentos.

Coelho, P.A.; Ramos-Porto, M.; Barreto, A.V.; Costa, V.E. (1982). Crescimento em viveiro de cultivo do camarão canela Macrobrachium amazonicum (Decapoda, Palaemonidae). Revista Brasileira de Zoologia, 1, 45-49.

Collart, O. O., \& Magalhães, C. (1994). Ecological constraints and life history strategies of palaemonid prawns in Amazonia. Internationale Vereinigung für theoretische und angewandte Limnologie: Verhandlungen, 25(4), 2460-2467. https://doi.org/10.1080/03680770.1992.11900670

Damasceno, K. S. F. S. C. (2007). Farinha dos Resíduos do Camarão Litopenaeus vannamei: Caracterização e Utilização na Formulação de Hambúrguer [Tese de doutorado]. Recife (PE): Universidade Federal de Pernambuco.

Damásio, M. H. \& Silva, M. A. A. P. (1996). Curso de treinamento em análise sensorial. Apostila Campinas: Fundação Tropical de Tecnologia "André Tosello".

Dutcosky, S. D. (2011). Análise sensorial de alimentos. (3a ed.), Champagnat, 426.

Furuya, W. M., Hayashi, C., Silva, A. B. M. D., Santos Júnior, O. D. O., Souza, N. E. D., Matsushita, M., \& Visentainer, J. V. (2006). Composição centesimal e perfil de ácidos graxos do camarão-d'água-doce. Revista Brasileira de Zootecnia, 35(4), 1577-1580. https://doi.org/10.1590/S1516-35982006000600001

Gildberg, A., \& Stenberg, E. (2001). A new process for advanced utilisation of shrimp waste. Process Biochemistry, 36(8-9), 809-812. https://doi.org/10.1016/S0032-9592(00)00278-8

Goes, E. S. D. R., Souza, M. L. R. D., Michka, J. M. G., Kimura, K. S., Lara, J. A. F. D., Delbem, A. C. B., \& Gasparino, E. (2016). Fresh pasta enrichment with protein concentrate of tilapia: nutritional and sensory characteristics. Food Science and Technology, 36(1), 76-82. https://doi.org/10.1590/1678-457X.0020

Guimarães, I. G., de Miranda, E. C., Ribeiro, V. L., Martins, G. P., \& de Miranda, C. C. (2008). Farinha de camarão em dietas para tilápia do Nilo (Oreochromis niloticus). Revista Brasileira de Saúde e Produção Animal, 9(1).

Islam, M., Sarker, M. N. I., Islam, M. S., Prabakusuma, A. S., Mahmud, N., Fang, Y., \& Xia, W. (2018). Development and quality analysis of protein enriched instant soup mix. Food and Nutrition Sciences, 9(6), 663-675. https://doi.org/10.4236/fns.2018.96050

Leningher, A. L.; Nelson, D. L. \& Cox, M. M. (1995). Princípios de Bioquímica. Editora Sarvier.

Maciel, C.R. \& Valenti, W.C. (2009). Biology, fisheries and aquaculture of the Amazon River Prawn Macrobrachium amazonicum: a review. Nauplius, 17(2), 61-79.

Moles, P. \& Bunge, J. (2002). Shrimp farming in Brazil: an industry overview. Fao/Wwf/Naca, 26 p.

Monteiro, M. L. G., Mársico, E. T., Lázaro, C. A., Ribeiro, R. O., Jesus, R. S., \& Conte-Júnior, C. A. (2014). Flours and instant soup from tilapia wastes as healthy alternatives to the food industry. Food Science and Technology Research, 20(3), 571-581. https://doi.org/10.3136/fstr.20.571

Ogawa, M., Maia, E. L., Fernandes, A. C., Nunes, M. L., Oliveira, M. E. B. D., \& Freitas, S. T. (2007). Waste from the processing of farmed shrimp: a source of carotenoid pigments. Food Science and Technology, 27(2), 333-337. https://doi.org/10.1590/S0101-20612007000200022

Portella, C. D. G., Sant'Ana, L. S., \& Valenti, W. C. (2013). Chemical composition and fatty acid contents in farmed freshwater prawns. Pesquisa Agropecuária Brasileira, 48(8), 1115-1118. https://doi.org/10.1590/S0100-204X2013000800043

Rahman, M. A., Saifullah, M., \& Islam, M. N. (2012). Fish powder in instant fish soup mix. Journal of the Bangladesh Agricultural University, 10(452-2016$35550), 145-148$.

Roversi, F. (2018). Análise da influência da atividade de carcinicultura sobre aspectos hidro-morfodinâmicos e de qualidade da água de corpos d'água costeiros: um estudo de caso no sistema lagunar de Guaraíras, RN. Tese (Doutorado) - Curso de Pós-graduação em Engenharia Oceânica, COPPE, Universidade Federal do Rio de Janeiro, Rio de Janeiro.

Sánchez-Camargo, A. P., Meireles, M. Â. A., Lopes, B. L. F., \& Cabral, F. A. (2011). Proximate composition and extraction of carotenoids and lipids from Brazilian redspotted shrimp waste (Farfantepenaeus paulensis). Journal of Food Engineering, 102(1), 87-93. https://doi.org/10.1016/j.jfoodeng.2010.08.008

Silva, D. J. \& Queiroz, A. C. (2002). Análise De Alimentos: Métodos Químicos e Biológicos. (3a ed.). Universidade Federal de Viçosa, p. 235.

Souza, M. L. R., Urbich, A. V., Müller, B.O., Coradini, M. F., Oliveira, G. G., Matiucci, M. A., \& Goes, E. S.R. (2021). Sopa instantânea com inclusão de farinhas de peixes. Research, Society and Development, 10(8), e35910817247-e35910817247. http://dx.doi.org/10.33448/rsd-v10i8.17247

Stevanato, F. B., Petenucci, M. E., Matsushita, M., Mesomo, M. C., Souza, N. E. D., Visentainer, J. E. L., \& Visentainer, J. V. (2007). Avaliação química e sensorial da farinha de resíduo de tilápias na forma de sopa. Food Science and Technology, 27, 567-571. https://doi.org/10.1590/S0101-20612007000300022

Tilami, S. K. \& Sampels, S. (2018). Nutritional value of fish: lipids, proteins, vitamins, and minerals. Reviews in Fisheries Science \& Aquaculture, 26(2), 243253. https://doi.org/10.1080/23308249.2017.1399104

Vasconcelos, B. M. F. (2015). Utilização da Macroalga Gracilaria birdiae no Desenvolvimento de Produtos Alimentícios [Dissertação de Mestrado]. Mossoró (RN): Universidade Federal Rural do Semi-Árido. 
Research, Society and Development, v. 10, n. 12, e416101220219, 2021

(CC BY 4.0) | ISSN 2525-3409 | DOI: http://dx.doi.org/10.33448/rsd-v10i12.20219

Viebig, R. F. \& Nacif, M. A. L. (2007). Nutrição aplicada à atividade física e ao esporte. In: Silva, S. M. C. S.; Mura, J. D. P. Tratado de alimentação, nutrição e dietoterapia. Roca, Cap. 16, p. 215-234.

Zakaria, Z., Hall, G. M., \& Shama, G. (1998). Lactic acid fermentation of scampi waste in a rotating horizontal bioreactor for chitin recovery. Process Biochemistry, 33(1), 1-6. https://doi.org/10.1016/S0032-9592(97)00069-1 